\title{
What effect does gun-related violence have on the attractiveness of a residential area? The case of Stockholm, Sweden
}

Mats Wilhelmsson

Department of Real Estate Management, KTH Royal Institute of Technology, Stockholm, Sweden

Vania Ceccato

Department of Urban Planning and Environment, KTH Royal Institute of Technology, Stockholm, Sweden, and

Manne Gerell

Department of Criminology, Malmö Universitet, Malmö, Sweden

\begin{abstract}
Purpose - This study aims to analyse the effect of gun-related violence on housing values, controlling for the area's crime levels and locational factors. Previous studies that aimed to find a causal connection between crime and housing values used instrument variables to solve the endogeneity problem. Here, the authors have instead been able to take advantage of the fact that shootings have occurred in random time and space. This has made it possible to estimate models to create windows around the shooting (event) and to estimate the causal effects of the shootings. Thus, the authors aim to contribute to the regression discontinuity design method in this context to estimate the short-term effects.

Design/methodology/approach - Using the regression discontinuity design method, the authors can estimate the short-term effects of shootings.

Findings - Findings from the analysis indicate that shootings directly affect those who are impacted by shootings and indirectly affect the environments where shootings occur. The indirect effect of shootings is momentary as it is capitalised directly in housing values in the immediate area. The effect also appears to be relatively long-term and persistent as housing values have not returned to the price level before the shooting 100 200 days after the shooting. The capitalisation effect is higher the closer one gets to the central parts of the city. On the other hand, the capitalisation effect is not higher or lower in areas with a higher crime rate per capita.

Originality/value - The article contributes to the previous literature in several ways. First and foremost, it provides an explicit analysis of shootings in built-up areas and their hypothesised effect on property prices through the impact on attractiveness and perceived safety. As far as the authors know, no study has analysed this issue on the international level or in Sweden. In this way, the authors aim to develop a study that can provide critical knowledge about one of the adverse effects of shootings. The authors also contribute to the literature by utilising unique data material, which allows the authors to merge information from the police about the exact location of shootings in the Stockholm area with data on sales of apartments in the same residential areas. In addition to the exact location of the shootings (coordinates), the authors also have access to data about whether the shootings led to injuries or deaths. Thus, the authors have separated the effect of shootings and fatal shootings, which has not been done before. Finally, the authors set out to highlight the results as a contribution to the debate on shootings.
\end{abstract}

Keywords Gun violence, Shootings, Fear, Housing values, GIS, Regression discontinuity design

Paper type Research paper

\section{JEL Classification - C21, O18, R31}

(C) Mats Wilhelmsson, Vania Ceccato and Manne Gerell. Published by Emerald Publishing Limited. This article is published under the Creative Commons Attribution (CC BY 4.0) licence. Anyone may reproduce, distribute, translate and create derivative works of this article (for both commercial and noncommercial purposes), subject to full attribution to the original publication and authors. The full terms of this licence may be seen at http://creativecommons.org/licences/by/4.0/legalcode

Bostad 2.0, Stockholm Police Headquarters, Säkraplatser nätverkt.

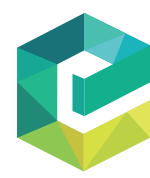

Received 6 March 2021

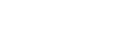


JERER

15,1

\section{Introduction}

The attraction value of a dwelling lies partly in its characteristics, such as size and quality, and partly in its location. The importance of location has long been the subject of research. In classical theories, housing value is linked to transportation costs to and from the city centrethe further from the centre, the higher the transport costs and the lower the housing value (or land value). Improved communications thus positively affect the attractiveness of a dwelling. In addition to a dwelling's relationship to the city centre, housing value is also affected by characteristics in the immediate area. It may involve both positive externalities, such as proximity to water, parks and natural beauty, but it can also involve the existence of negative externalities, such as crime.

One form of crime is gun-related violence. The rate of deadly violence has been largely stable in Sweden in the last decade, but an increase in shootings has recently been observed (Sturup et al., 2019). In 2020, the number of shootings was the highest ever recorded (The Swedish Police Authority [1]). According to the Swedish National Council for Crime Prevention (2017), close to $40 \%$ of all homicides in Sweden are committed with a firearm, and a considerable number of individuals are injured and wounded in firearm-related violence (Khoshnood, 2018). The number of outsiders affected by this gang-related violence has also increased. In 2020, more than 350 shootings were reported, and just under $15 \%$ of these led to deaths. More than 140 of these shootings were in the Stockholm area. This can be compared with around 80-90 shootings per year in 2018 and 2019. Levels of worry among the general population, as measured through surveys, are the highest since the measurements started, at nearly half (47\%) of the population, and the number has increased since 2017 (BRA, 2020). Even if the average person does not have to feel anxious from a purely statistical point of view, previous research indicates that the sound of gunshots or knowledge of shootings reduces residents' perceptions of safety (Zaluar, 2012). It has also been shown that neighbourhood violence can affect children and their school test results (Sharkey et al., 2012, 2014; Gershensson and Tekin, 2015; Caudilho and Torche, 2014; Monteiro and Rocha, 2017). The impact on children translates into long-term effects on income in adulthood, with more violence during childhood resulting in lower incomes as an adult (Sharkey and TorratsEspinosa, 2017). Although previous research has found that fear and levels of victimisation (separately and/or combined) impact a residential area's attractiveness, measured as housing value (Wilhelmsson and Ceccato, 2015; Ceccato and Wilhelmsson, 2012, 2020), studies specifically focused on the effect of gross violence, such as gun violence, on a residential area's attractiveness are lacking. As gun violence differs from most other types of violence, due to a loud, discernible noise across a large area, it may have a bigger impact than less noticeable crime. Such an effect can also be amplified by the extensive media coverage of gun violence compared to other types of violence.

Therefore, the following study aims to contribute to the field by analysing the effect of gun-related violence on housing values, controlling for the area's crime levels and locational factors. Using the regression discontinuity design method, we can estimate the short-term effects of shootings. Previous studies that aimed to find a causal connection between crime and housing values used instrument variables to solve the endogeneity problem. Here, we have instead been able to take advantage of the fact that shootings have occurred in random time and space. This has made it possible to estimate models to create windows around the shooting (event) and to estimate the causal effects of the shootings. Thus, we aim to contribute to the regression discontinuity design method in this context to estimate the shortterm effects.

In addition, the article contributes to the previous literature in several ways. First and foremost, it provides an explicit analysis of shootings in built-up areas and their hypothesised effect on property prices through the impact on attractiveness and perceived safety. As far as we know, no study has analysed this issue on the international level or in Sweden. In this way, 
we aim to develop a study that can provide critical knowledge about one of the adverse effects of shootings. We also contribute to the literature by utilising unique data material, which allows us to merge information from the police about the exact location of shootings in the Stockholm area with data on sales of apartments in the same residential areas. In addition to the exact location of the shootings (coordinates), we also have access to data about whether the shootings led to injuries or deaths. Thus, we have separated the effect of shootings and fatal shootings, which has not been done before. Finally, we set out to highlight the results as a contribution to the debate on shootings.

The term gun-related violence is used in this paper as a synonym for shooting, gun violence, gun injury and firearm injury - terms which are used interchangeably. The outcome of a firearm injury can be lethal, fatal or not. In this study, we assess the impact of both outcomes on property prices.

The outline for the remainder of the paper is as follows: section two presents shootings as a phenomenon in the urban environment. What are the causes and developments in the last 10 20 years, and how has mass media coverage of these events changed? This section will also discuss the effect of shootings on the perceived safety in residential areas. Section three will briefly present the theoretical framework, the hedonic theory and the chosen empirical method - the regression discontinuity design method. Section four will present the empirical analysis in detail. Section five offers a conclusion and description of policy implications.

\section{The impact of crime and fear on the attractiveness of a residential area: theory and hypotheses}

Diverse elements of the urban environment are valued differently by residents. However, what is certain is that no matter what they value, buyers are willing to pay a premium for attractive views (Jim and Chen, 2009). The opposite is also true: signs of physical deterioration and poor management are often determinants of crime and fear in neighbourhoods, which affect the area's attractiveness and housing markets (e.g. Gibbons, 2004; Ceccato and Wilhelmsson, 2011).

Five decades of research confirms that crime has a significant impact on property prices (Thaler, 1978; Naroff et al., 1980; Rizzo, 1979; Dubin and Goodman, 1982; Clark and Cosgrove, 1990; Tita et al., 2006; Munroe, 2007; Ceccato and Wilhelmsson, 2017, 2019; Wilhelmsson and Ceccato, 2015; de Graaff and Zietz, 2020; McIlhatton et al., 2016). The impact of crime on the housing market does not seem to be the same across different types of crime and is highly dependent on the nature of the event. In the UK, for instance, a study by Gibbons (2004) showed that only criminal damage affected housing prices negatively, while in Stockholm, residential burglary has been shown to result in more significant drops in prices. The remaining question is thus whether such an effect can be observed for shootings. In the next section, we discuss the nature and potential effect of shootings on property prices.

\subsection{Shootings as a phenomenon in the housing market}

A shot fired against a person or a target in a particular setting has an impact far beyond that particular place and tends to reverberate over time and space, affecting residents, communities and, ultimately, the overall housing market (Figure 1).

The first most obvious impact is on the victim. This takes the form of injuries to the target (who or what the bullet is intended to hit) with different degrees of seriousness, up to the death or destruction of the target. The second effect involves injuries to unrelated individuals/ targets and victim(s), who are situationally but unintentionally present at the moment of the shooting (who happen to be "in the wrong place, at the wrong time"). The third relates to the "damage" to other settings and people who can feel, smell or hear the sounds of gunfire, which 


\section{JERER 15,1}

Figure 1.

The adverse impact of shootings on housing markets: individual, neighbourhood and city-wide effects

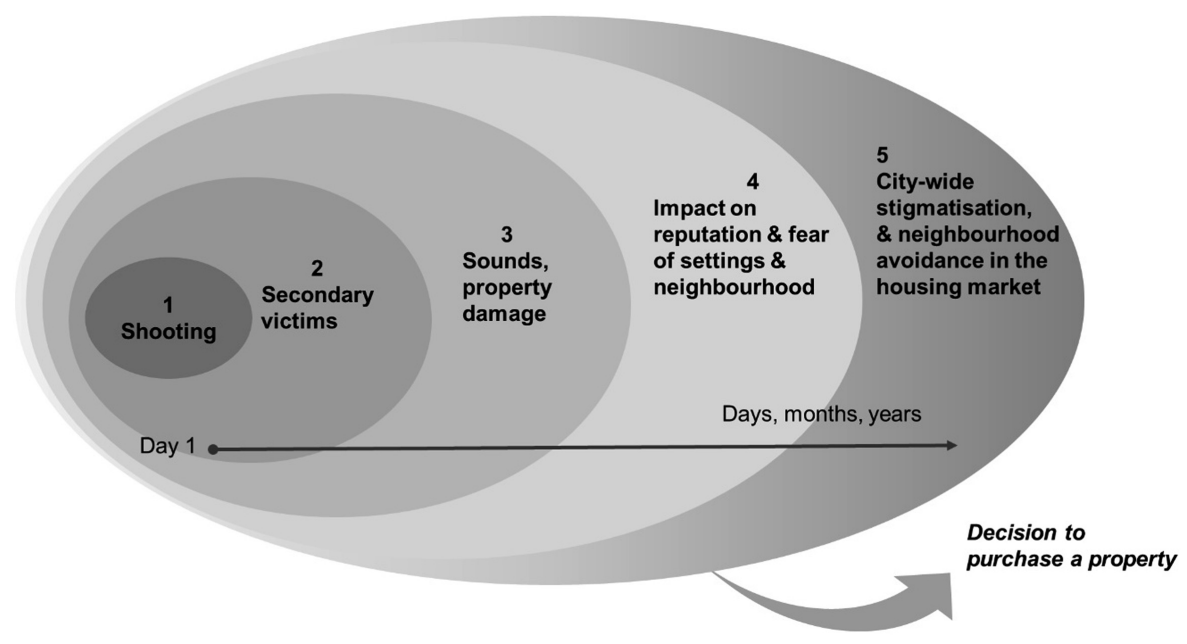

might be "felt, seen or heard" by the closest residents. However, this effect can be unevenly distributed in the neighbourhood (see, e.g. Zaluar, 2012) depending on the urban landscape and conditions of the shooting. These effects are felt seconds and minutes after the shooting. As soon as knowledge of the shooting spreads locally to the police and emergency services, the impact sets in on residents in the neighbourhood and persists for days or months to come (Sharkey et al., 2014). Media may inform the public of the shooting almost immediately as it happens, and the reputation of the area might be damaged for years to come if the event is paired with other events that indicate no one is in control of the area. Wilson and Kelling (1982) suggest that physical deterioration and public disorder function as symbols of the extent to which a neighbourhood is in decline. This is not only because signs of physical deterioration are often visible but also because they depict a much broader range of problems: they are more informative to residents than official crime statistics (Skogan, 1990). Shootings alone may not create this spiral of decay but can contribute to it. The decline of a residential area may translate into an increasing desire to move, weaker attachment to the area among residents (Steenbeek and Hipp, 2011; Hipp and Steenbeek, 2016; Skogan, 1990) and lower property values, thus making the area less attractive to new buyers. Because of the damaged reputation and underlying safety conditions in the area, which perpetuates perceptions of safety risk among residents and visitors, those who can afford to purchase a property in this type of neighbourhood may be able to take advantage of highly discounted property prices years after the shooting.

\section{Theoretical and methodology framework}

To estimate the effect of shootings, we have used the hedonic method, which assumes that individuals maximise their benefit, given a budget constraint. In the utility function, the consumption of housing is found together with all other goods. Rosen (1974) showed that the interpretation of individual parameter estimates regarding the attributes that make up a home could be regarded as the marginal willingness to pay for the attribute in question. Here we assume that crime, or lack of crime, is an important attribute that describes the residential area. Shooting is a form of crime that naturally receives a great deal of attention in the media, among other places. It may not be an entirely random event, but it can still be considered random when it happens. 
Furthermore, it is reasonable that the effect is relatively local both in time and space. Therefore, we have chosen to estimate the effect of shootings on property values with the hedonic approach, but we isolate individual shootings in time and space. We have done this by applying the so-called regression discontinuity design (RDD) methodology (Imbens and Lemieux, 2008). In principle, it is based on the fact that we create windows around the event, partly based on when the shooting occurs in time and partly where the shooting occurs. Only property sales in the immediate vicinity of the shooting are included in the estimation. One of the main reasons an RDD approach is designed is to minimise endogeneity (see Gelati and Moessner, 2018). The method was first introduced in Thistlewaite and Campbell (1960).

Similar to classical regression analysis, RDD is based on observational data, i.e. nonexperimental data. The difference is that RDD is considered as one of the methods that identify the parameters most effectively. It allows us, at least locally, to interpret treatment effects as causal effects. What makes this possible is that observations can be based on an objective measure depending on whether an observation has been given treatment or not. One primary assumption is that there is a sharp cut-off level (the time and place of the shootings). If the person is below this cut-off, they do not get treatment (do not belong to the control group). Here, it can be translated to before the shooting or, if after the shooting, far away geographical from the shooting.

We have estimated the effect in three steps. We have first deflated property prices to check for the general rise in prices that has taken place during the period we are analysing. Second, we have estimated a hedonic regression discontinuity design model where we have only included transactions directly related to the gunfire incident in time and space. Finally, we have estimated the aggregate effect by analysing all the estimated effects of shootings.

The deflation of the individual transaction prices has been done by dividing the nominal prices by a deflator. The deflator has been estimated by estimating a hedonic price equation with binary variables over time, i.e. we have estimated a hedonic price index according to traditional methods (Song and Wilhelmsson, 2010). The hedonic price equation for estimating price development over time has the following form:

$$
H P_{i}=\alpha_{k}+\theta_{1, t} Y M_{i}+\mu_{i}
$$

where $H P$ is equal to nominal transaction price with the subscript $i$ equal to a transaction. The subscript $k$ indicates the municipality, and subscript $t$ indicates a period. The vector YM is equal to a binary variable indicating the year and month the dwelling was sold. The deflated house prices $(\overline{H P I})$ have been calculated by dividing the nominal prices with the deflator $(\widehat{H P})$ times 100, equal to the estimated prices from equation (1). Thus, the deflated house prices are in an index form, where a change in one unit corresponds to one percentage point. The nonparametric version of the hedonic price equation, in the RDD context, takes the form:

$$
\begin{aligned}
\overline{H P I}_{i, j}= & \alpha_{j}+\tau_{j} T_{j}+\beta_{0, j}\left(D_{j, i}-c 1_{j}\right)+\beta_{1, j} T_{j}\left(D_{j, i}-c 1_{j}\right)+\beta_{2, j}\left(L_{i, j}-c 2_{j}\right)+\beta_{3, j} T_{j}\left(L_{i, j}-c 2_{j}\right) \\
& +\beta_{4, j} X_{i}+\varepsilon_{i}
\end{aligned}
$$

where $c 1$ and $c 2$ are the cut-offs, and $T$ is a binary variable equal to one if $D>c 1$ and $L<c 2$. The variable $D$ is equal to the date of the shooting, and $L$ is equal to the shooting location. $X$ is a vector of dwelling attributes. The difference between $D$ and $L$ and their respective cut-offs are the so-called running variables. Letting $h 1$ and $h 2$ be the bandwidths of the data used, we have $c 1-h 1<D<c 1+h 1$ and $L<c 2+h 2$. This means that dwelling transaction $h 1$ days before the shooting and $h 1$ days after the shooting is included in the data used; simultaneously, the geographical distance from the shootings does not exceed $h 2$ kilometres. The subscript $i$ is the number of transactions, and subscript $j$ is equal to the individual shootings. 
JERER 15,1

The parameter $\tau$ is the regression discontinuity (RD) estimate of interest together with $\beta_{0}$ and $\beta_{1}$. The hypothesis is that it is negative - that is, a shooting has an adverse impact on house prices. This means that we will have several estimates of the effect, one for each shooting (j). The parameter $\beta_{0}$ measures the real price development. If it is significantly different from zero, there is a real price increase or decrease. Parameter $\beta_{1}$ measures whether the real price development after the shooting differs from the real price development before the shooting. If $\beta_{1}$ is not significantly different from zero, then the real price development is the same both before and after the shooting. The parameter $\tau$ could be considered the more short-term effect of a shift in property values, while $\tau$ and $\beta_{1}$ measure the more long-term (or medium-term) effect.

Underlying $\mathrm{RD}$ assumptions for internal validity are discussed in, for example, Imbens and Lemieux (2008) and Jacob et al. (2012). They are (1) that the running variable (here time and location) cannot be affected or caused by the treatment and (2) that the cut-off point is entirely independent of the running variable (exogenously given). Hence, whether the transaction has received treatment or not depends entirely on whether the dwelling has been sold before or after the cut-off date and close in location to the shooting or not. Moreover, it also depends on (3) whether it simultaneously (same cut-offs) has taken other actions for covariates and (4) whether it is possible to manipulate if one is on one side or the other of the cut-off. Additional conditions are (5) that it is only the treatment status that is discontinuous, which means that there must be no other actions that were implemented on the same date. Finally, (6) it is assumed that the functional form between the running variable and the outcome variable (here dwelling price) can be represented by a continuous function in the absence of the treatment (as we assume in equation (2)).

The average effect is equal to the sum of all $j$ effects divided by the number of shootings. As noted, attributes that describe the dwelling are also included. These consist of, among other things, the size of the dwelling. However, it is unnecessary to include attributes that describe the residential area as the variation within the "windows" we have created is low for these attributes.

In the third step, we have estimated the relationship between separate shootings on property prices, as well as the relationship between property prices and the location of a shooting and whether the shooting led to injuries and deaths. The following equation has been used to estimate the meta-analysis regarding individual gunfire incidents:

$$
\tau_{j}=\gamma_{0}+\gamma_{1} C B D_{j}+\gamma_{2} I_{j}+\gamma_{3} M_{j}+\varepsilon_{j}
$$

where $C B D$ is equal to the distance to the central business district, $I$ is equal to the number of injuries and $M$ is equal to the number of deaths. When estimating the individual RD effects, it was unnecessary to include attributes that describe the individual residential areas where the shootings took place. However, when we analyse variation in the RD estimates, individual housing attributes must be included to understand why some shootings have a more significant effect than others.

Four variations of equation (3) have been estimated. The first model includes all gunfire incidents, which have been estimated with OLS. The second model has also been estimated with OLS but only includes the statistically significant capitalisation effects. Models 3 and 4 include all gunfire incidents but have been estimated with either a spatial autoregressive (SAR) or a spatial error (SEM) specification. Here, we have used a spatial weight matrix, where the inverse distance measures the spatial relationship between the shootings.

\section{Empirical analysis}

\subsection{The study area}

The case study area is limited to the municipality of Stockholm (Figure 2), which is the capital of Sweden, with a total population of 975,904 in 2019 (SCB - Statistics Sweden, 2020). 


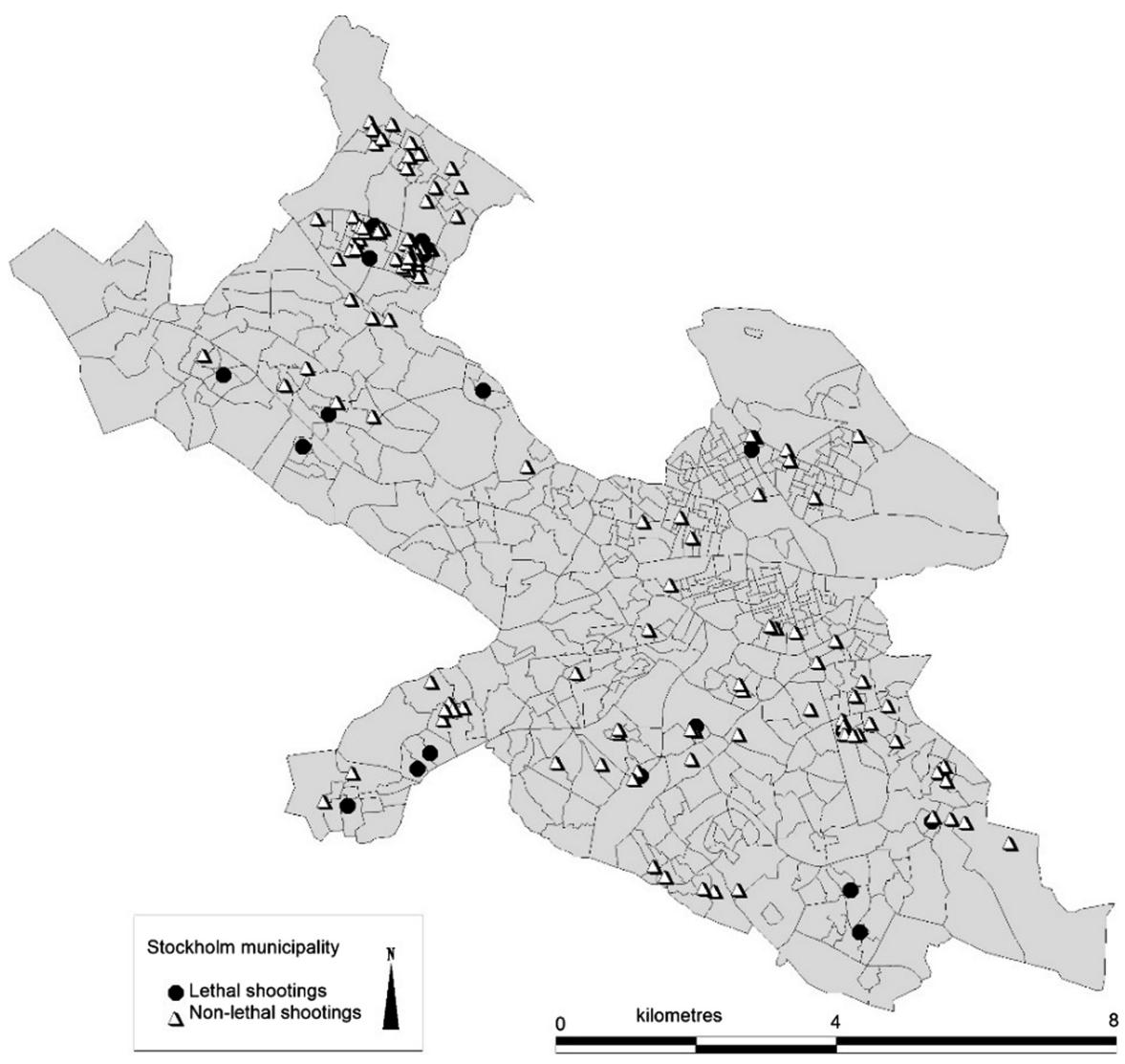

Gun-related violence

Stockholm is located on Sweden's east coast, and the central parts of the city consist of 14 islands that are continuous with the Stockholm archipelago. The islands are well-connected by roads and an efficient public transportation system, comprised of buses, the Stockholm metro, national rail networks and commuter rail. The main public transport junction is located in the CBD, in the inner city's central area. The geographical distribution of crime has been fairly stable over the last 40 years, with violent crime mostly concentrated in the inner city and a few outskirt areas (west and south) (Wikström, 1991; Ceccato et al., 2002; Uittenbogaard and Ceccato, 2012; Ceccato and Wilhelmsson, 2020). Shootings are rare events in Stockholm, but in 2020, the number of shootings reached a new high (The Swedish Police Authority [1]), often linked to gang-related groups in which victims are poor young males who often have a history of involvement with criminal activities.

Shootings are expected to affect the citizen's perception of the places where these shootings occur and beyond, namely, through the sound of gunfire and indirectly through media and word-of-mouth communication. The Stockholm Safety Survey shows that the majority of the adult population in the city of Stockholm do not worry about crime, even though crime events tend to happen more often in Stockholm Municipality than in the rest of the country (the total recorded crime rate was 115 per 1,000 inhabitants, while the rate for the country as a whole was 71 per 1,000 inhabitants). However, when residents in one of the areas with a higher concentration of shootings and crime were asked if they would move away from 
JERER 15,1

the area if they could, $26 \%$ of the respondents answered "yes". For all respondents from the city of Stockholm, this figure was only $6 \%$. Similar figures were found when residents were asked about their fear of crime and worry about future victimisation (Stockholm municipality, 2020). The geographical distribution of fear has tended to remain constant since the safety survey started in 2008 (Stockholm municipality, 2020).

\section{6}

\subsection{Data and descriptive statistics}

The data obtained from the police authority contain data on all reported shootings in Stockholm Municipality between 2017 (April) and 2018 (full year). In total, there were 98 shootings, or illegal firearm discharges, which may be a more accurate term. We accessed information on location in terms of latitude and longitude, date, time and the number of killed or injured. In total, there were 12 killed and 35 injured. A large number of shootings thus have zero killed or injured. According to the police, "a confirmed shooting is when projectiles were fired with gunpowder-laden weapons and that there are traces of this in the form of bullets, sleeves or damage to materials or people coming from the shooting, or that there is more than one independent eyewitness to the shooting" [2]. The shooting must also be illegal and not manifestly unintentional. Figure 3 illustrates where the shootings took place in Stockholm. The shootings are not evenly distributed in space but there are apparent cluster formations where there have been more shootings, something we need to consider when estimating the effect of shootings on property values.

The information regarding shootings will be merged with data on home sales in the Stockholm area in the years 2017-2019. The statistics source is Mäklarstatistik AB, which is an interest organisation for real estate brokers in Sweden. According to Mäklarstatistik AB's own information, their sales reporting includes an overwhelming majority of all sales that have taken place through a broker (80-90\%). Any selection problems are expected to be

Figure 3.

Shootings in the Stockholm area 20172019 (Västerort)

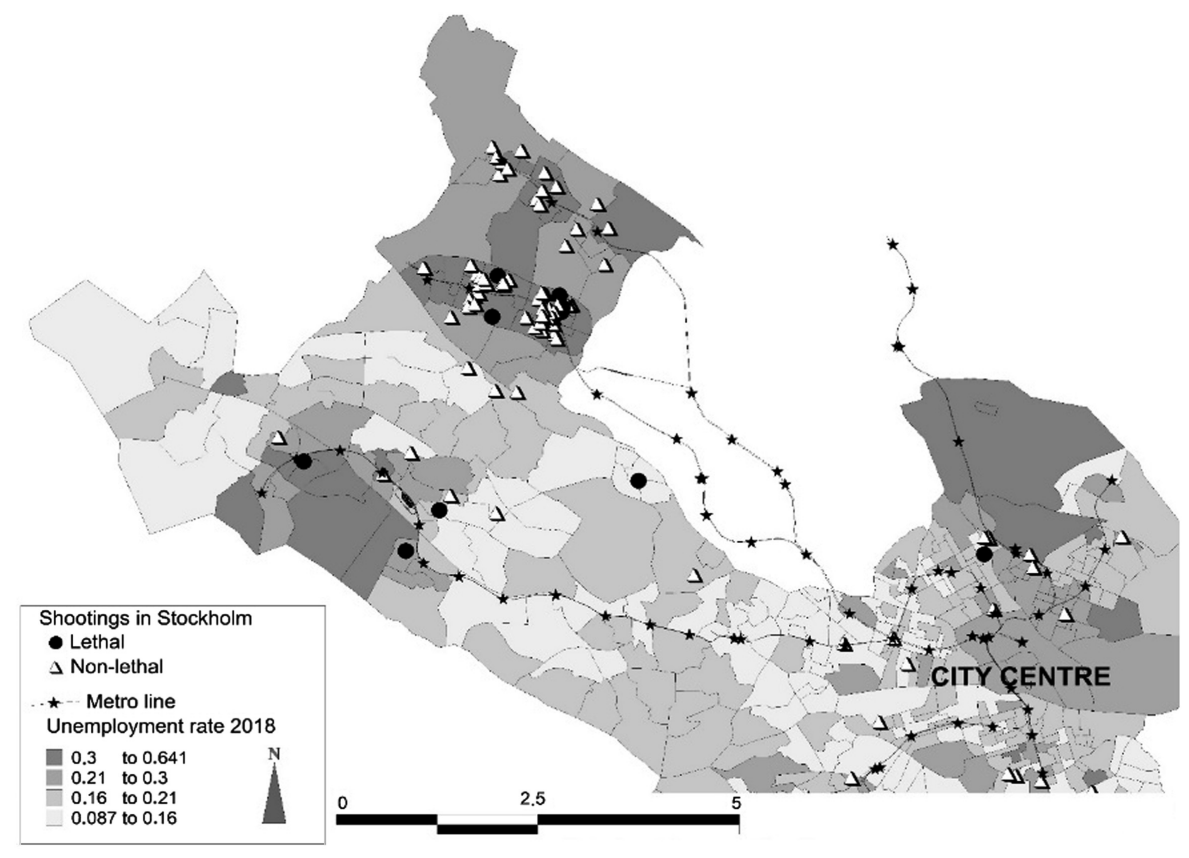


small. We will analyse the effect of shootings on property prices for owner-occupied apartments as well as single-family houses. The statistics refer to the transaction prices, date of sale, number of rooms, living space, latitude and longitude for all transactions, as well as monthly housing association fees for condominium sales. The most important thing is that we can relate all sales to shootings via date, latitude and longitude. In addition to apartment and property attributes, we have also included variables such as distance to the city centre and distance to a metro station.

We have also included the distance from each dwelling to the nearest shooting, regardless of when it has taken place in time. This variable will be used to create a window in space for which dwellings are affected by a shooting. Dates will be used to create a so-called running variable (a window in time) that measures the time (number of days) from a shooting. Figure 3 shows the assumptions we make regarding bandwidths and cut-offs and defines the treatment and control area in time and space.

In the default model of equation (2), we assume that the shooting effect impacts the housing values within a radius of 1 kilometre $(c 1)$ from the shooting, and the "time window" is set to 200 days before and after the shooting $(h 1)$. The treatment group consists of the sales that have taken place 200 days after the shooting and closer than 1 kilometre from the shooting $(c 2)$, while the control group consists of the transactions that have taken place 200 days before the shooting and within a radius of $1-10$ kilometres from the shooting $(h 2)$. Figure 4 illustrates the assumptions made about $c 1, c 2, h 1$ and $h 2$ in the default model.

Table 1 presents descriptive statistics for housing transactions. The table also presents the deflated transaction prices calculated from a hedonic model with binary monthly variables. The descriptive statistics show some noteworthy results. The total number of transactions in Stockholm County over the period 2017-2019 amounted to approximately

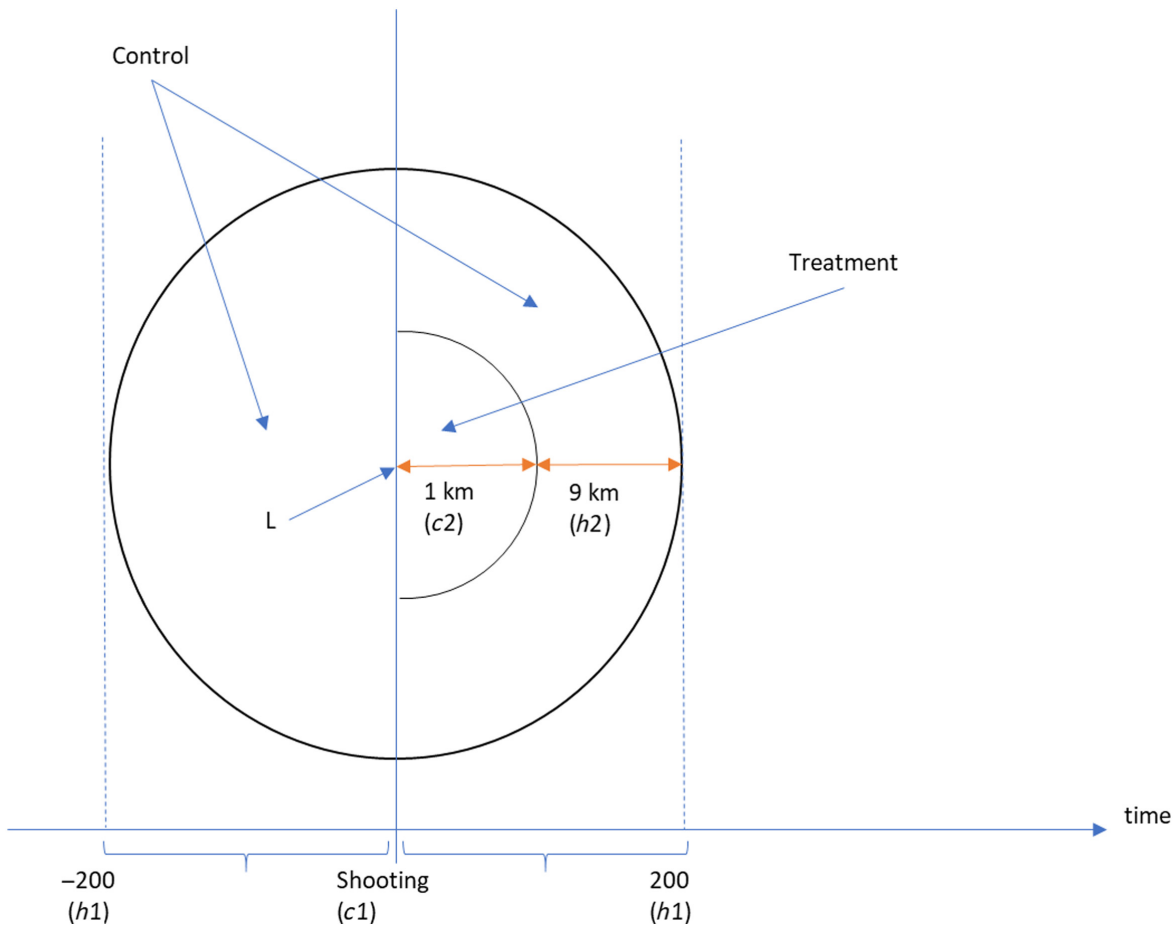

Figure 4. Definition of treatment and control area 


\begin{tabular}{|c|c|c|c|c|}
\hline \multirow{6}{*}{$\begin{array}{l}\text { JERER } \\
15,1\end{array}$} & & Definition & Average & Standard deviation \\
\hline & All & & & \\
\hline & HP & Nominal housing price (SEK) & $3,484,663$ & $1,840,457$ \\
\hline & HPI & Real house price (index) & 99.24 & 2.54 \\
\hline & LA & Living area (square metres) & 66.72 & 25.36 \\
\hline & $\mathrm{MF}$ & Monthly fee (SEK) & 3626.92 & 1399.38 \\
\hline \multirow{14}{*}{48} & $R$ & Number of rooms & 2.58 & 1.08 \\
\hline & $A$ & Age (years) & 47.91 & 36.82 \\
\hline & $\mathrm{CBD}$ & Distance to CBD (kilometres) & 10.88 & 10.91 \\
\hline & Metro & Distance metro station (kilometres) & 4.60 & 9.20 \\
\hline & & Nearest distance to a shooting (kilometres) & 13.62 & 9.76 \\
\hline & No. of observations & & 68,484 & \\
\hline & Treatment and contr & roup & & \\
\hline & $\mathrm{HP}$ & Nominal housing price (SEK) & $3,725,427$ & $1,873,012$ \\
\hline & HPI & Real house price (index) & 99.38 & 2.57 \\
\hline & LA & Living area (square meter) & 65.36 & 24.82 \\
\hline & $\mathrm{MF}$ & Monthly fees (SEK) & 3522.67 & 1317.24 \\
\hline & $R$ & Number of rooms & 2.54 & 1.05 \\
\hline & $A$ & Age (years) & 50.52 & 37.61 \\
\hline & CBD & Distance to CBD (kilometres) & 7.28 & 4.94 \\
\hline \multirow{3}{*}{$\begin{array}{l}\text { Table 1. } \\
\text { Descriptive statistics } \\
\text { (2017-2019) }\end{array}$} & Metro & Distance metro station (kilometres) & 1.64 & 2.16 \\
\hline & LS & Nearest distance to a shooting (kilometres) & 10.42 & 3.56 \\
\hline & No. of observations & & 57,369 & \\
\hline
\end{tabular}

68,000. The effective number of transactions used in the hedonic RDD model was approximately 58,000. Here, however, one must be careful with the interpretation. Some property sales were close in time and space to multiple shootings and are thus included several times in the reduced sample. It could be interpreted that this effectively creates 98 different samples, but individual housing transactions can be included in several samples. On average, properties close to a shooting have a slightly higher transaction price as they are slightly larger and somewhat newer, but the differences are not statistically significant. We can also note that homes close to a shooting in terms of time and space are also slightly closer to Stockholm's CBD. On average, the housing transactions are 3 kilometres closer to a shooting incident in the reduced sample, where only transactions in the control and treatment area are included.

\subsection{Regression discontinuity design analysis}

Figure 5 presents the estimates for $\tau$ for all 98 shootings. The estimate of the effect of shootings on property prices has been estimated for each shooting that has taken place from 2017 (March) to 2018, where location information is available. A total of 98 RDD models have been estimated. In $66 \%$ of these, a negative $\tau$ value has been estimated. The distribution of the capitalisation effect has its centre of gravity to the left of zero, i.e. shootings have reduced property prices. On average, the effect amounts to 1.7 percentage points and the average $t$-value amounts to -2.8 , which means that the estimate is significantly different from zero. We can note an outlier with a remarkably high value, but it is not a statistically significant estimate. If non-significant $\mathrm{RD}$ estimates are excluded, the average effect is equal to 5.5 percentage points, which corresponds to SEK 204,900 for an average owner-occupied apartment. The RD plot shows the estimated impact at the time of the shooting on the average property value. The capitalisation effect is estimated to be, on average, around SEK 60,000. We present all the hedonic RDD models' estimates for first and last shooting, which we analyse in Appendix. 

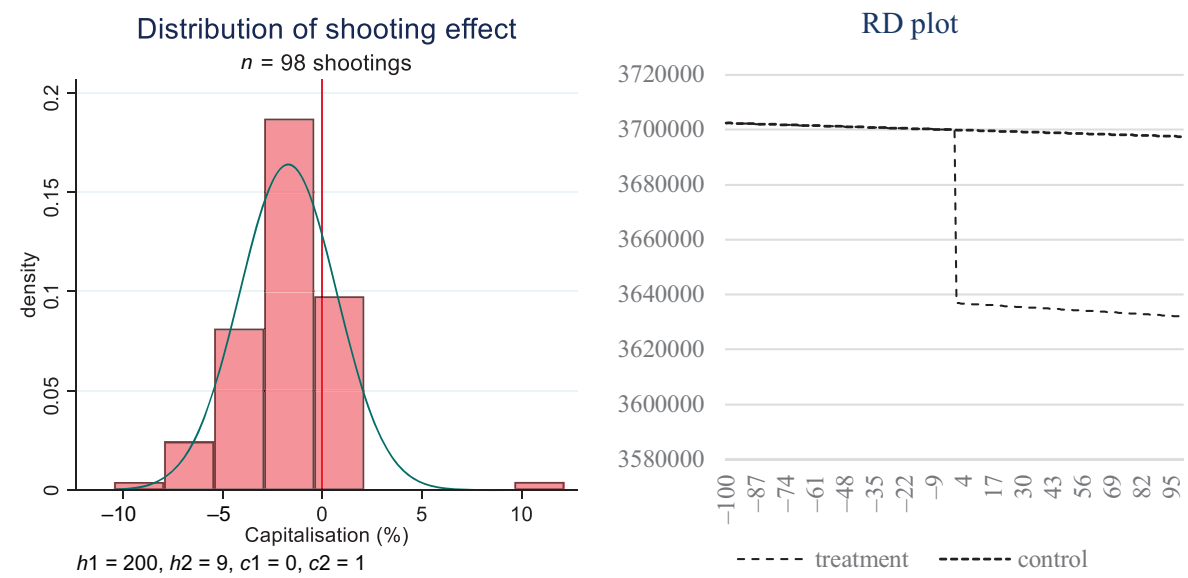

Gun-related violence

\subsection{Testing underlying RDD assumptions}

Three specification tests are discussed in Imbens and Lemieux's study (2008). The first test is that the independent variables should exhibit continuity at cut-off. If one finds such discontinuity, it speaks clearly against the assumptions of the RDD. We have tested any discontinuity regarding the variable dwelling size and the variable monthly fee to the housing association. If the result from the estimation of equation (2), but with dwelling size and monthly fee as the outcome variable, shows no such discontinuity (see results in Figures 6a and $6 \mathrm{~b}$ ), it strengthens our conclusions that shootings have a negative capitalisation on property prices.

The second test tests whether there is a discontinuity at other points of the running variable, i.e. where there should be no jump (the so-called placebo effect). Imbens and Lemieux recommend testing an alternative cut-off value equal to the median between cut-off and bandwidth length before and after treatment. Since we have two cut-off values where we limit both time and space, we have performed the test slightly differently. We test the placebo effect by randomly assigning when and where the shooting took place. Hence, each observation in the sample will have a random shift in time and space, that is, $\left(D_{i, j}+\mu_{i, 1}\right)$ and $\left(L_{i, j}+\mu_{i, 2}\right)$. By assuming a normal distribution $\left(\mu_{i} \sim N\left(0, s_{i}\right)\right)$ around the running variables 1 and 2, we estimate equation (2). The hypothesis is that the shootings will not have a significant effect on price. For running variable 1 , we have assumed an average value of 0 with a standard deviation of 10 days, and for running variable 2 , we have assumed a mean value of 0 with a standard deviation of 20 kilometres. If the estimates from these placebo models show no discontinuity effect, they further strengthen our conclusion that shootings harm a residential area's attractiveness through a deterioration in property values. The results are shown in Figure 6c.

The third specification test, initially suggested by McCrary (2007), refers to a discontinuity in the density. Finding such discontinuity is not conclusive evidence against the RDD's assumptions, but it indicates that it is necessary to extend the analysis. We have divided the days before and after shootings into 16 parts (bins) containing 25 days. We have calculated the number of transactions in each part for each shooting and then calculated the average value of all shootings. What we want is for the number of transactions to be approximately equal before and after the shootings. Figure $6 \mathrm{~d}$ shows the results from this specification test.

We conclude that there is no discontinuity regarding the living area (Figure 6a). The average effect is equal to -0.007 , and only $21 \%$ of the estimates show significant estimates. 


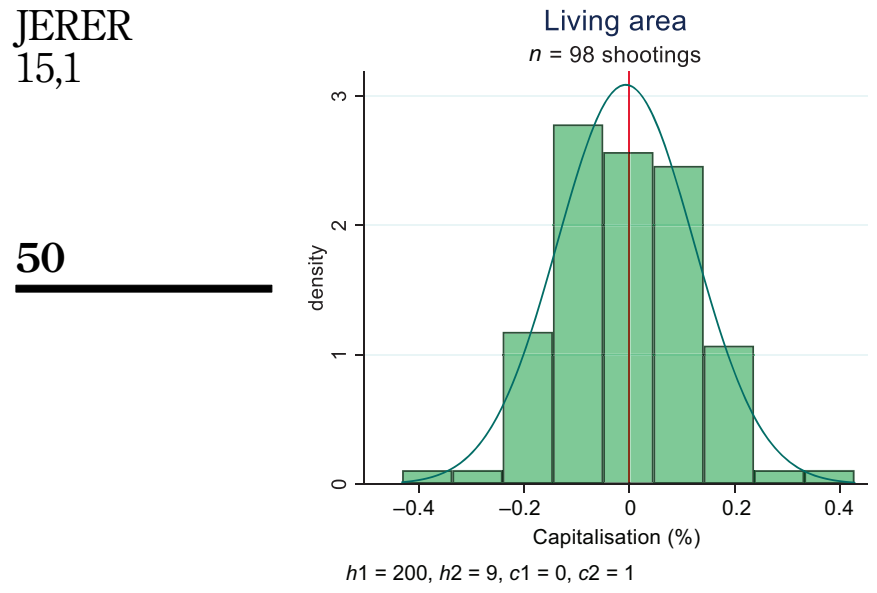

(a)

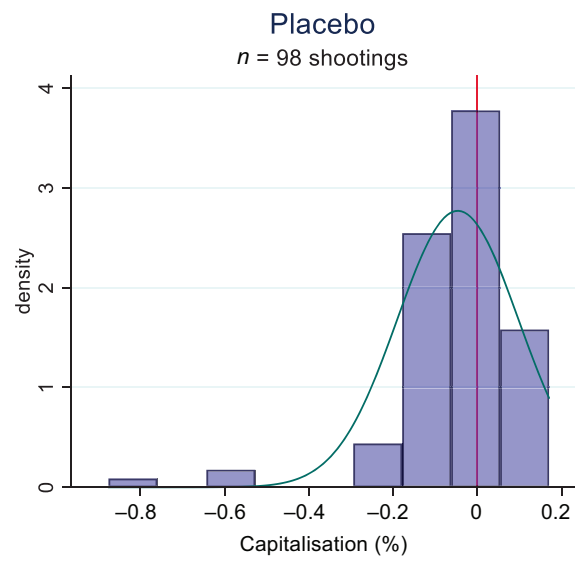

$h 1=200, h 2=9, c 1=0, c 2=1$

(c)

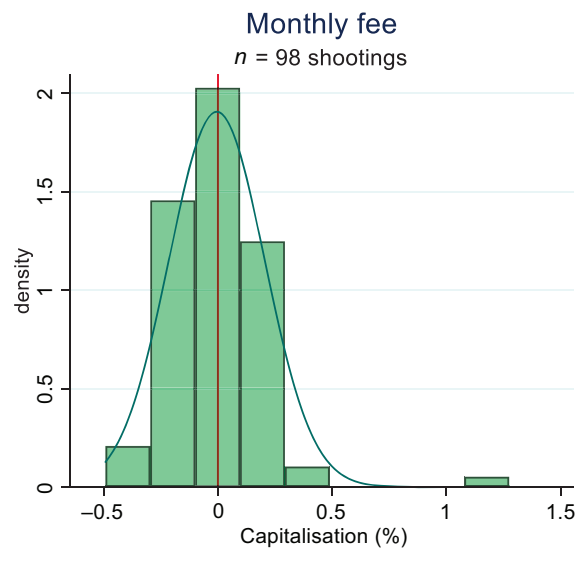

$h 1=200, h 2=9, c 1=0, c 2=1$

(b)

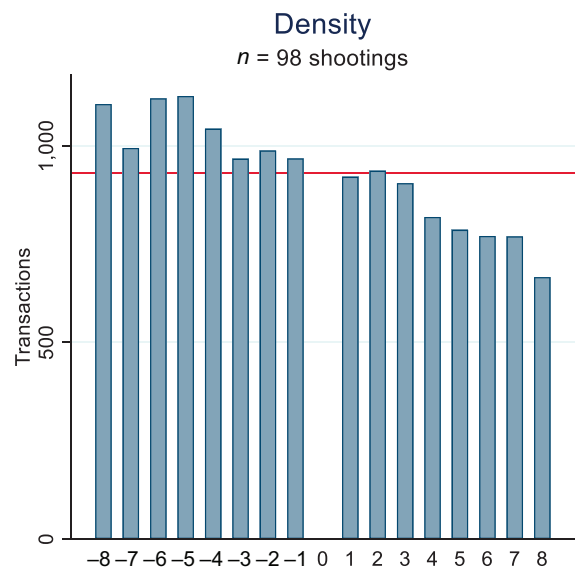

(d)

However, more than half of these are positive estimates, which would suggest higher prices, not lower prices. That is, we have a positive bias in our estimation of the capitalisation effect. The conclusion is the same for the apartment attribute monthly fee (Figure 6b). Here, too, approximately every fifth estimate is significantly different from zero, and more than half of these are negative, which would also indicate a positive bias in the capitalisation effect. Against the background that the average effects are small, and only a few are significant, we conclude that the capitalisation effect of shootings is reliable.

The average placebo effect is only 0.04 percentage points with an average $t$-value of only -0.34 , strengthening our results of the capitalisation effect (Figure 6c). Only $9 \%$ of the estimates are statistically significant.

The density test shows that the number of transactions is higher before the shootings than after (Figure 6d). In the interval -3 to 3 (75 days before and after the shooting), however, the 
number of transactions is relatively stable. Two things may explain this: (1) there has been a general trend towards fewer transactions on the market, which can also be observed in the vicinity of where shootings have taken place; (2) our transaction data are truncated from the right, which means that for shootings in the latter part of 2019, we have no transactions 200 days after the shooting. For the later shooting dates, we only have home sales up to 100 days after the shooting. In addition to the specification tests, we also perform a robustness test of the bandwidth's assumptions.

\subsection{Bandwidths and cut-off assumptions}

Figures $7 \mathrm{a}$ and $7 \mathrm{~b}$ show the results from alternative bandwidth assumptions. When we look at assumptions about window size in time and space, we can state that the estimates and the capitalisation effect are relatively stable, which is, of course, desirable. If the period before and
Gun-related violence

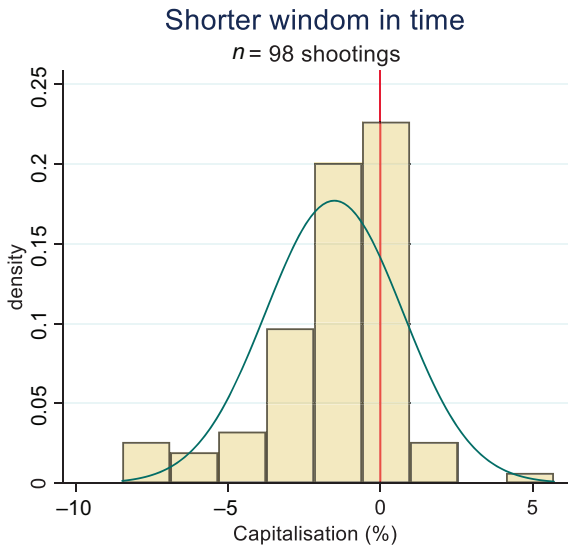

$h 1=100, h 2=9, c 1=0, c 2=1$

(a)

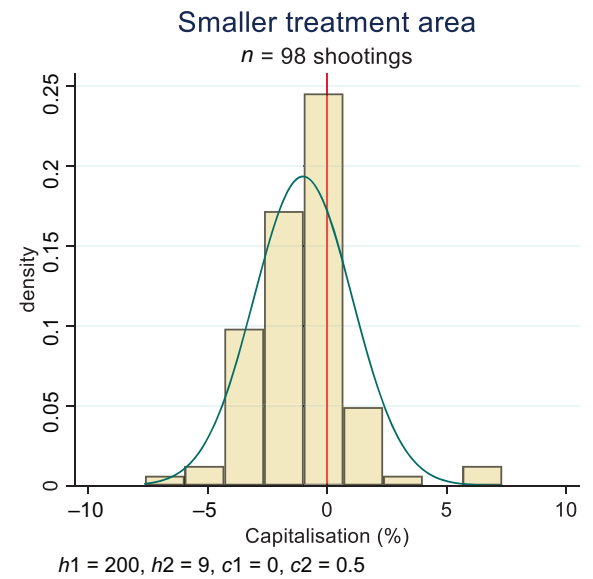

(c)

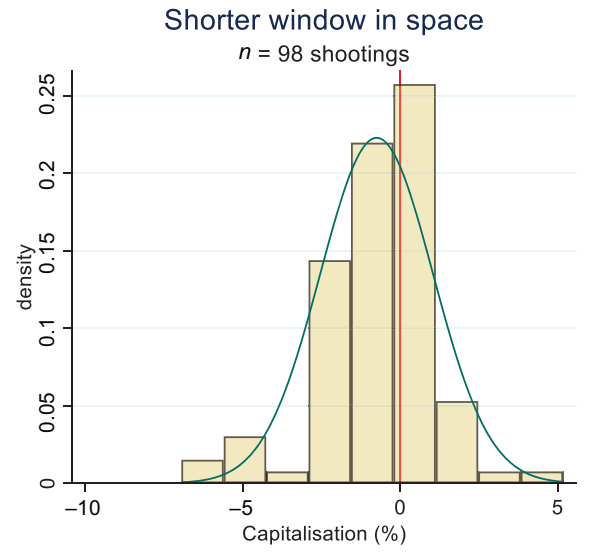

$h 1=100, h 2=4, c 1=0, c 2=1$

(b)

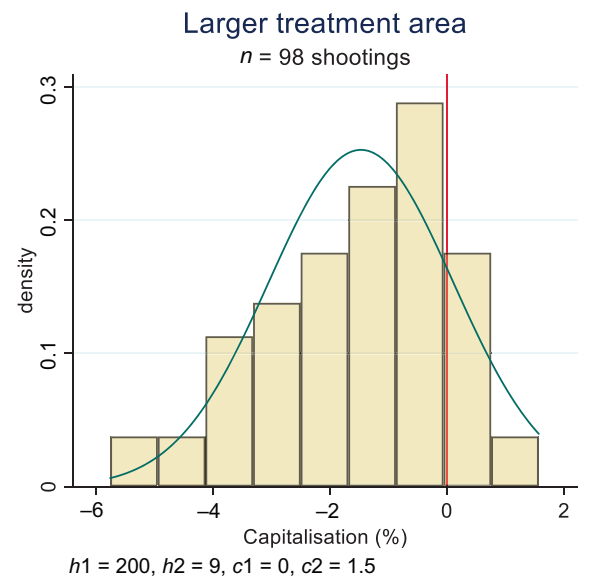

(d)
Figure 7.

Alternative bandwidth assumptions 
JERER

15,1

52

after the shooting is shorter in time (100 days instead of 200), we can note that the estimates are relatively normally distributed and that the midpoint is slightly to the left of zero, i.e. the estimate is still negative (Figure 7a). If we limit the control area to only 4 kilometres from the shooting instead of 10 kilometres, we can also state that the capitalisation effect is still negative (Figure $7 b$ ).

We also test whether the assumption of the treatment area in space has influenced our interpretation of the capitalisation effect. By reducing the treatment area to 0.5 kilometres from the shooting (Figure 7c), we can state that the effect is slightly smaller; while if we increase it to 1.5 kilometres (Figure $7 \mathrm{~d}$ ), the capitalisation effect is more significant. This may be because the effect is not local, and the shooting has a significant effect over a broader geographical area. However, when we limit the area to 0.5 kilometres, the number of property transactions decreases significantly, making it challenging to interpret the result statistically. In summary, however, we can conclude that the estimate of the capitalisation effect is relatively stable even when we relax the assumptions about the treatment and control group's size.

\subsection{Explaining the variation of the RD estimates}

We can note that the capitalisation effect of shootings on property values varies, but we can also note both short-term and long-term effects in most shootings. The question is whether the variation in the capitalisation effect (RD estimates) can be explained by when the shooting took place, where it took place and whether the shooting led to injury or death. Regardless of the effect of a shooting, it has a news value, but news coverage can potentially be greater if the shooting leads to severe consequences. The effect of a shooting on property values can also differ if it takes place in an area that already has a high-crime rate compared to a nearby area with a relatively low crime rate. To analyse the variation in the capitalisation effect, we have related it to where the shooting took place in Stockholm with the distance to the CBD and the distance to a metro station, the number of injured and dead during the shooting and the crime rate per capita in the residential area. Table 2 below presents descriptive statistics regarding the variables included in the model.

The average capitalisation effect over the 98 shootings amounts to 1.7 percentage points with an estimated standard deviation of 2.43 percentage points. The CBD distance from each shooting is approximately 8 kilometres with a standard deviation of 3 kilometres. This means that most of the shootings have taken place in the suburbs around Stockholm's inner city. The number of injuries in these shootings is, on average, 0.32 people, and the number of deaths is 0.10 persons, which means that more serious injuries are relatively uncommon. The shootings have taken place in residential areas where the total crime rate amounts to 0.34 crimes per capita. Here, the standard deviation is large, indicating that shootings occur regardless of whether the area is affected by major underlying crime or not.

\begin{tabular}{llcc}
\hline & Definition & Average & Standard deviation \\
\hline RD estimate & Capitalisation effect (percentage unit) & -1.70 & 2.43 \\
CBD & Distance to CBD (kilometres) & 8.29 & 3.17 \\
Metro & Distance to a metro station (kilometres) & 0.57 & 0.52 \\
$I$ & Injuries (count) & 0.3265 & 0.4714 \\
$M$ & Deaths (count) & 0.1020 & 0.3043 \\
$C$ & Crime per capita & 0.3432 & 0.3464 \\
$T$ & Period & 49.5 & 28.43 \\
No. of observations & & 98 & \\
\end{tabular}

Table 2.

Descriptive statistics 
Table 3 shows the result from equation (3): the variation in the 98 adjacent areas' capitalisation effect explained by certain underlying factors. Hypotheses that we test are, for example, that shootings that lead to injuries or deaths will have a greater capitalisation effect than shootings that do not lead to personal injuries. We also test the hypotheses that proximity to the inner city and subway stations affects the capitalisation effect and that the capitalisation effect has changed over time as more shootings have occurred. Four models have been estimated. The first two are estimated with OLS, where the first refers to all 98 shootings. The second model refers only to those shootings that show a statistically significant capitalisation effect. The two concluding models refer to models that are intended to control for spatial dependence.

Relatively little of the variation observed in the capitalisation effect can be explained by included variables. The independent variables can explain only $20 \%$ of the variation. Whether someone has been injured or died in the shooting does not impact the capitalisation effect. However, the distance to CBD has a more significant impact. The capitalisation effect is greater closer to the CBD. The effect has not become either greater or lesser over time. Controlling for spatial dependency, none of the independent variables, except distance to $\mathrm{CBD}$ in the SAR model, can explain the capitalisation effect's spatial variation. The SAR model is also the preferred model based on AIC.

\section{Conclusion and policy implications}

The study shows that shootings have a small but significant impact on property prices, and that the impact of shootings stretches beyond those who are directly affected by shootings.

\begin{tabular}{|c|c|c|c|c|c|}
\hline & $\begin{array}{l}(1) \\
\text { OLS } 1\end{array}$ & $\begin{array}{l}(2) \\
\text { OLS } 2\end{array}$ & $\begin{array}{l}(3) \\
\text { SAR }\end{array}$ & $\begin{array}{l}(4) \\
\text { SEM }\end{array}$ & \\
\hline Death & $\begin{array}{l}0.00518 \\
(0.01)\end{array}$ & $\begin{array}{c}0.214 \\
(0.32)\end{array}$ & $\begin{array}{l}-0.180 \\
(-0.27)\end{array}$ & $\begin{array}{l}-0.0377 \\
(-0.06)\end{array}$ & \\
\hline Injuries & $\begin{array}{l}0.101 \\
(0.20)\end{array}$ & $\begin{array}{c}0.580 \\
(1.26)\end{array}$ & $\begin{array}{l}0.0277 \\
(0.06)\end{array}$ & $\begin{array}{c}0.168 \\
(0.40)\end{array}$ & \\
\hline Distance to CBD & $\begin{array}{l}-0.284^{* * * *} \\
(-3.83)\end{array}$ & $\begin{array}{l}-0.206^{*} \\
(-2.36)\end{array}$ & $\begin{array}{l}-0.152^{*} \\
(-2.11)\end{array}$ & $\begin{array}{l}-0.154 \\
(-1.88)\end{array}$ & \\
\hline Distance to metro station & $\begin{array}{l}0.387 \\
(0.86)\end{array}$ & $\begin{array}{l}0.0109 \\
(0.02)\end{array}$ & $\begin{array}{l}0.0837 \\
(0.21)\end{array}$ & $\begin{array}{c}0.372 \\
(0.81)\end{array}$ & \\
\hline Crime per capita & $\begin{array}{l}1.120 \\
(1.63)\end{array}$ & $\begin{array}{l}1.244 \\
(1.57)\end{array}$ & $\begin{array}{c}0.859 \\
(1.41)\end{array}$ & $\begin{array}{c}0.988 \\
(1.61)\end{array}$ & \\
\hline Time & $\begin{array}{l}0.00782 \\
(0.95)\end{array}$ & $\begin{array}{l}-0.0109 \\
(-1.40)\end{array}$ & $\begin{array}{l}0.0107 \\
(1.46)\end{array}$ & $\begin{array}{l}0.0131 \\
(1.89)\end{array}$ & \\
\hline Constant & $\begin{array}{l}-0.373 \\
(-0.41)\end{array}$ & $\begin{array}{l}-1.030 \\
(-0.98)\end{array}$ & $\begin{array}{l}-0.495 \\
(-0.61)\end{array}$ & $\begin{array}{l}-1.092 \\
(-1.20)\end{array}$ & \\
\hline $\begin{array}{l}W \\
\text { treat_coef }\end{array}$ & & & $\begin{array}{l}0.661^{* * * *} \\
(4.38)\end{array}$ & & \\
\hline e.treat_coef & & & & $\begin{array}{l}0.876^{* * * *} \\
(8.10)\end{array}$ & \\
\hline I var(e.treat_coef) & & & $\begin{array}{l}3.923 * * * \\
(6.98)\end{array}$ & $\begin{array}{l}3.846^{* * * *} \\
(6.92)\end{array}$ & \\
\hline $\begin{array}{l}\text { Observations } \\
R^{2} \\
\text { AIC }\end{array}$ & $\begin{array}{l}98 \\
0.201 \\
443.4\end{array}$ & $\begin{array}{l}62 \\
0.222 \\
243.6\end{array}$ & $\begin{array}{c}98 \\
432.0\end{array}$ & $\begin{array}{r}98 \\
432.6\end{array}$ & \\
\hline \multicolumn{5}{|c|}{$\begin{array}{l}\text { Note(s): } t \text { statistics in parentheses } \\
{ }^{*} p<0.05,{ }^{* *} p<0.01,{ }^{* * * * *} p<0.001\end{array}$} & $\begin{array}{r}\text { Table } 3 . \\
\text { RD estimate model } \\
\text { (equation (3)) }\end{array}$ \\
\hline
\end{tabular}


JERER

15,1

\section{4}

The effect of shootings has a temporal dimension. Our results indicate that the indirect effect of a shooting is momentary as it is capitalised directly in housing values in the immediate area. However, the effect also appears to be relatively long-term and persistent as housing values have not returned to the price level before the shooting after 100-200 days. In addition, the capitalisation effect is higher the closer one gets to Stockholm inner city areas (not necessarily the CBD, see Figure 2). Typically, properties in the more central areas are always in high demand due to their location in attractive homeowner areas (therefore characterised by low housing mobility, well-connected to transportation infrastructure and with lower crime rates than the outskirts of the CBD), which means that if something dramatic happens, such as a shooting, the effect is noticed and the reputation of the area may be damaged, at least for a period of time.

On the other hand, it is not evident that the capitalisation effect becomes higher (or lower) in areas with a higher (or lower) crime rate per capita. One reason for this is that property prices in high-crime areas are already discounted because of the damaged reputation (Figure 2), which means that the willingness to pay will not be reduced because of a single shooting among many other criminogenic events. Conversely, all other things being equal, shootings in low-crime areas will be seen as rare, one-off events, disconnected from the residential area's overall quality and property prices will therefore not be affected. Another contextual factor that is important to consider is that shootings are rare events in Sweden compared to countries in which lethal violence happens on an everyday basis (e.g. Zaluar, 2012). In practice, this means that the fear being victimised by a shooting is still relatively low, even in Stockholm's high-crime areas, and the capitalisation effect of shootings is therefore not reflective of the area's crime levels.

These results have important theoretical and practical implications. First, shootings have an impact that is not temporally or spatially homogenous and should not be understood as a fixed effect that is intrinsic to a particular area; rather, they are a phenomenon worthy of further investigation in particular sectors of Stockholm's housing markets. Second, some of these effects are related to the circumstances surrounding individual shootings; others are related to the interactions between the situational conditions surrounding the shooting and the underlying locational and socio-economic conditions of the area. Another important theoretical contribution is that it is difficult to disentangle the selective effect of shootings from the impact of other crimes on the quality and reputation of an area. Therefore, a policy recommendation is that shootings - like any other crime event - should not be considered in isolation but rather as a symptom of intertwined criminogenic conditions triggered by mechanisms reaching far beyond a particular residential area. Through the impact shootings have on property prices, they can also exacerbate a "spiral of decay" (Skogan, 1990) in which neighbourhoods that see many shootings lose resources and become more deprived, fuelling a cycle of deprivation, crime and fear.

\section{Notes}

1. https:/polisen.se/om-polisen/polisens-arbete/sprangningar-och-skjutningar/

2. Translation from Swedish. https://polisen.se/om-polisen/polisens-arbete/sprangningar-ochskjutningar/

\section{References}

BRÅ, Brottsförebyggande rådet (The Swedish National Council for Crime Prevention) (2017), Konstaterade fall av dödligt våld - En granskning av anmält dödligt våld 2016 [Detected Cases of Deadly Violence - A Review of Reported Deadly Violence 2016] Brottsförebyggande rådet, National Council of Crime Prevention, Stockholm. 
BRÅ, Brottsförebyggande rådet (The Swedish National Council for Crime Prevention) (2020), The Swedish National Crime Victims Survey 2018, BRA, Stockholm.

Caudilho, M.L. and Torche, F. (2014), "Exposure to local homicides and early educational achievement. in Mexico", Sociology of Education, Vol. 87 No. 2, pp. 89-105.

Ceccato, V. and Wilhelmsson, M. (2011), "Crime and its impact on apartment prices. The case of Sweden”, Geografiska Annaler: Serie C, Vol. 93 No. 1, pp. 81-103.

Ceccato, V. and Wilhelmsson, M. (2012), "Acts of vandalism and fear in neighbourhoods: do they affect housing prices?", Chapter in the Urban Fabric of Crime and Fear, Springer.

Ceccato, V. and Wilhelmsson, M. (2017), "Does crime impact real estate prices? An assessment of accessibility and location", The Oxford Handbook of Environmental Criminology, Oxford University Press, ISBN 9780190279707, 2018.

Ceccato, V. and Wilhelmsson, M. (2019), "Do crime hot spots affect housing prices?”, Nordic Journal of Criminology, pp. 1-19, doi: 10.1080/2578983X.2019.1662595.

Ceccato, V. and Wilhelmsson, M. (2020), “Do crime hot spots affect housing prices?”, Nordic Journal of Criminology, Vol. 21 No. 1, pp. 84-102, doi: 10.1080/2578983X.2019.1662595.

Ceccato, V., Haining, R. and Signoretta, P. (2002), "Exploring crime statistics in Stockholm using spatial analysis tools", Annals of the Association of American Geographers, Vol. 22, pp. 29-51.

Clark, D.E. and Cosgrove, J.C. (1990), "Hedonic prices, identification and the demand for public safety", Journal of Regional Science, Vol. 30, pp. 105-121.

de Graaff, J. and Zietz, J. (2020), "The impact of crime on apartment prices in Hamburg, Germany", Journal of European Real Estate Research, Vol. ahead-of-print No. ahead-of-print, doi: 10.1108/ JERER-11-2019-0047.

Dubin, R.A. and Goodman, A.C. (1982), "Valuation of education and crime neighborhood characteristics through hedonic housing prices", Population and Environment, Vol. 5, pp. 166-181.

Gelati, G. and Moessner, R. (2018), "What do we know about the effects of macroprudential policy?", Economica, Vol. 85, pp. 735-770.

och Gershenson, S. and Tekin, E. (2015), The Effect of Community Traumatic Events on Student achievement: Evidence from the Beltway Sniper attacks, NBER Work. Pap. 21055, National Bureau of Economic Research, Cambridge, MA.

Gibbons, S. (2004), “The costs of urban property crime*”, The Economic Journal, Vol. 114 No. 499, pp. F441-F463, doi: 10.1111/j.1468-0297.2004.00254.x.

Hipp, J.R. and Steenbeek, W. (2016), "Types of crime and types of mechanisms: what are the consequences for neighborhoods over time?", Crime and Delinquency, Vol. 62 No. 9, pp. 1203-1234.

Imbens, G.W. and Lemieux, T. (2008), "Regression discontinuity design: a guide to practice”, Journal of Econometrics, Vol. 142, pp. 615-635.

Jacob, R., Zhu, P., Somers, M.-A. and Bloom, H. (2012), A Practical guide to regression discontinuity, MDRC publication, It can be downloaded on the Website, available at: www.mdrc.org.

Jim, C.Y. and Chen, W.Y. (2009), "Value of scenic views: hedonic assessment of private housing in Hong Kong”, Landscape and Urban Planning, Vol. 91 No. 4, pp. 226-234.

Khoshnood, A. (2018), "Firearm-related violence in Sweden - a systematic review", Aggression and Violent Behavior, Vol. 42, pp. 43-51.

McCrary, J. (2007), "Testing for manipulation of the running variable in the regression discontinuity design", Journal of Econometrics, Vol. 142, pp. 698-714.

Mcllhatton, D., McGreal, W., Taltavul de la Paz, P. and Adair, A. (2016), "Impact of crime on spatial analysis of house prices: evidence from a UK city", International Journal of Housing Markets and Analysis, Vol. 9 No. 4, pp. 627-647. 
JERER 15,1
Monteiro, J. and Rocha, R. (2017), "Drug battles and school achievement: evidence from Rio de Janeiro's Favelas", The Review of Economics and Statistics, Vol. 99 No. 2, pp. 213-28.

Munroe, D.K. (2007), "Exploring the determinants of spatial pattern in residential land markets: amenities and disamenities in charlotte, NC, USA", Environment and Planning B: Planning and Design, Vol. 34, pp. 336-354.

Naroff, J.L., Hellman, D. and Skinner, D. (1980), "Estimates of the impact of crime on property values", Growth and Change, Vol. 11 No. 4, pp. 24-30, doi: 10.1111/j.1468-2257.1980.tb00878.x.

Rizzo, M.J. (1979), "The effect of crime on residential rents and property values", The American Economist, Vol. 23 No. 1, pp. 16-21, available at: http://www.jstor.org/stable/25603200.

Rosen, S. (1974), "Hedonic prices and implicit markets: product differentiation in pure competition", Journal of Political Economy, Vol. 82 No. 1, pp. 34-55.

SCB - Statistics Sweden (2020), "Folkmängd och landareal i tätorter, per tätort. Vart femte år 1960 2019”, available at: https://www.statistikdatabasen.scb.se/pxweb/sv/ssd/START_MI_ MI0810_MI0810A/LandarealTatortN/(accessed 14 Febraury 2021).

Sharkey, P. and Torrats-Espinosa, G. (2017), "The effect of violent crime on economic mobility", Journal of Urban Economics, Vol. 102, pp. 22-33.

Sharkey, P.T., Tirado-Strayer, N., Papachristos, A.V. and och Raver, C.C. (2012), "The effect of local violence on children's attention and impulse control", American Journal of Public Health, Vol. 102 No. 12, pp. 2287-2293.

Sharkey, P., Schwartz, A.E., Ellen, I.G. and och Lacoe, J. (2014), "High stakes in the classroom, high stakes on the street: the effects of community violence on student's standardised test performance", Sociological Science, Vol. 1, pp. 199-220.

Skogan, W.G. (1990), Disorder and Decline: Crime and the Spiral of Decay in American Neighborhoods, University of California Press, Berkley, Los Angeles, CA.

Song, H.-S. and Wilhelmsson, M. (2010), "Improved price index for condominiums", Journal of Property Research, Vol. 27 No. 1, pp. 39-60.

Steenbeek, W. and Hipp, J.R. (2011), "A longitudinal test of social disorganization theory: feedback effects among cohesion, social control, and disorder”, Criminology, Vol. 49 No. 3, pp. 833-871.

Stockholm municipality (2020), Trygghet I Stockholm 2020. Resultat Från Stockholms Stads Trygghetsmätning: Staden Total, Rapport Stockholm stad, Stockholm.

Sturup, J., Rostami, A., Mondani, H., Gerell, M., Sarnecki, J. and Edling, C. (2019), "Increased gun violence among young males in Sweden: a descriptive national survey and international comparison”, European Journal on Criminal Policy and Research, Vol. 25 No. 4, pp. 365-378.

Thaler, R. (1978), "A note on the value of crime control: evidence from the property market”, Journal of Urban Economics, Vol. 5 No. 1, pp. 137-145.

Thistlewaite, D.L. and Campbell, D.T. (1960), "Regression-discontinuity analysis: an alternative to the ex-post facto experiment", Journal of Educational Psychology, Vol. 51, December, pp. 309-317.

Tita, G.E., Petras, T.L. and Greenbaum, R.T. (2006), "Crime and residential choice: a neighborhood level analysis of the impact of crime on housing prices", Journal of Quantitative Criminology, Vol. 22 No. 4, pp. 299-317.

Uittenbogaard, A.C. and Ceccato, V. (2012), "Space-time clusters of crime in Stockholm", Review of European Studies, Vol. 4, pp. 148-156.

Wikström, P.O.H. (1991), Urban Crime, Criminals, and victims: The Swedish Experience in an AngloAmerican Comparative Perspective, Springer, Stockholm.

Wilhelmsson, M. and Ceccato, V. (2015), "Does burglary affect property prices in a nonmetropolitan municipality?", Journal of Rural Studies, Vol. 39, pp. 210-218, doi: 10.1016/j.jurstud.2015.03.014.

Wilson, J.Q. and Kelling, G.L. (1982), "Broken windows”, Atlantic Monthly, Vol. 249, pp. 29-38.

Zaluar, A. (2012), "Turf war in Rio de Janeiro: youth, drug traffic, guns and hyper-masculinity", in Ceccato, V. (Ed.), The Urban Fabric of Crime and Fear, Springer, pp. 217-237. 
Appendix

Gun-related violence

\begin{tabular}{|c|c|c|c|}
\hline & $\begin{array}{l}(1) \\
\text { HPI }\end{array}$ & $\begin{array}{l}(2) \\
\text { HPI }\end{array}$ & \\
\hline$T$ & $\begin{array}{l}-6.141^{* * *} \\
(-5.81)\end{array}$ & $\begin{array}{l}-4.733^{* *} \\
(-3.03)\end{array}$ & 57 \\
\hline$\beta_{0}$ & $\begin{array}{l}0.00262 \\
(0.55)\end{array}$ & $\begin{array}{l}0.0156 \\
(0.66)\end{array}$ & \\
\hline$\beta_{1}$ & $\begin{array}{l}4.006^{* * * *} \\
(4.20)\end{array}$ & $\begin{array}{l}4.331^{* * *} \\
(3.04)\end{array}$ & \\
\hline$\beta_{3}$ & $\begin{array}{l}0.0678^{* * *} \\
(7.92)\end{array}$ & $\begin{array}{l}0.165^{* * *} \\
(14.64)\end{array}$ & \\
\hline$\beta_{4}$ & $\begin{array}{l}-0.000418 \\
(-1.49)\end{array}$ & $\begin{array}{l}0.000199 \\
(0.55)\end{array}$ & \\
\hline Subway & $0.210^{* * *}$ & $\begin{array}{l}0.332^{* * * *} \\
(14.15)\end{array}$ & \\
\hline CBD & $\begin{array}{l}-2.147^{* * * *} \\
(-69.44)\end{array}$ & $\begin{array}{l}-2.065^{* * * *} \\
(-42.39)\end{array}$ & \\
\hline LA & $\begin{array}{l}4.644^{* * *} \\
(53.26)\end{array}$ & $\begin{array}{l}4.990^{* * * *} \\
(41.17)\end{array}$ & \\
\hline$R$ & $\begin{array}{l}0.470^{* * *} \\
(6.84)\end{array}$ & $\begin{array}{l}0.491^{* * * *} \\
(5.63)\end{array}$ & \\
\hline$A$ & $\begin{array}{l}-0.848^{* * *} \\
(-17.49)\end{array}$ & $\begin{array}{l}-0.655^{* * * *} \\
(-10.60)\end{array}$ & \\
\hline$A$-squared & $\begin{array}{l}0.121^{* * *} \\
(12.89)\end{array}$ & $\begin{array}{l}0.0730^{\text {***** }} \\
(6.05)\end{array}$ & \\
\hline MF & $\begin{array}{l}-0.595^{* * *} \\
(-10.59)\end{array}$ & $\begin{array}{l}-1.174^{* * * *} \\
(-12.57)\end{array}$ & \\
\hline Constant & $\begin{array}{l}89.54^{* * * *} \\
(219.25)\end{array}$ & $\begin{array}{c}69.64 \\
(0.53)\end{array}$ & \\
\hline Observations & 7,729 & 5,271 & \\
\hline $\begin{array}{l}R^{2} \\
\text { AIC }\end{array}$ & $\begin{array}{c}0.787 \\
24833.7\end{array}$ & $\begin{array}{c}0.737 \\
17370.2\end{array}$ & $\begin{array}{l}\text { Table A1. } \\
\text { Hedonic RDD models }\end{array}$ \\
\hline $\begin{array}{l}\text { Note(s): } t \text { statistics in parentheses } \\
{ }^{*} p<0.05,{ }^{* * *} p<0.01,{ }^{* * * *} p<0.001\end{array}$ & & & $\begin{array}{r}\text { (1) first shooting, (2) } \\
\text { last shooting }\end{array}$ \\
\hline
\end{tabular}

\section{Corresponding author}

Mats Wilhelmsson can be contacted at: mats.wilhelmsson@abe.kth.se

For instructions on how to order reprints of this article, please visit our website:

www.emeraldgrouppublishing.com/licensing/reprints.htm

Or contact us for further details: permissions@emeraldinsight.com 